Hanna Idema \& Karen Phalet

\title{
Transmission of gender-role values in Turkish-German migrant families: The role of gender, intergenerational and intercultural relations
}

Transmission von Geschlechtsrollenvorstellungen in deutsch-türkischen Familien: die Rolle von Geschlecht, intergenerationalen und interkulturellen Beziehungen

\begin{abstract}
This study investigates how gender-role values of Turkish-German adolescents are shaped by intergenerational as well as intercultural relations. As part of a major survey of migrant families in Germany (Nauck, 2000), Turkish same-sex parent-child dyads $(\mathrm{N}=$ 405) were each asked separately about their gender-role values, about socialisation goals and styles in parent-child relations, and about degrees of acculturation and perceived discrimination in intercultural relations. Intergenerational discrepancies differed across gender. in that second-generation daughters showed a significant shift towards more egalitarian values, but sons remained as conservative as their fathers. To explain the adoption of egalitarian vs. conservative genderrole values by Turkish adolescents, sociodemographic, intergenerational and intercultural factors were entered as independent variables in analyses of covariance with adolescents' values as a dependent variable. As expected, adolescents who are more acculturated, as indicated by self-reported German language proficiency, are more egalitarian. In addition, we find most egalitarian values among daughters of more highly educated and more egalitarian mothers Conversely, father's religious socialisation goals and the perception of discrimination
\end{abstract}

\section{Zusammenfassung}

In dieser Studie wird untersucht, wie die Geschlechtsrollenvorstellungen türkisch-deutscher Jugendlicher sowohl durch intergenerationale als auch interkulturelle Beziehungen geprägt werden. Als Teil einer größeren Befragung von Einwandererfamilien in Deutschland (Nauck 2000) wurden ElternKind-Dyaden gleichen Geschlechts $(\mathrm{N}=405)$ getrennt voneinander über ihre Geschlechtsrollenvorstellungen, Sozialisationsziele und Erziehungsstile in den Eltern-Kind-Beziehungen, sowie über das Ausmaß von Akkulturation und wahrgenommener Diskriminierung in den interkulturellen Beziehungen befragt. Die Diskrepanz zwischen den Generationen unterschied sich je nach Geschlecht dahingehend, dass bei den Töchtern ein signifikanter Schub in Richtung egalitärer Wertvorstellungen auftrat, während die Söhne so konservativ wie ihre Väter blieben. Um die Annahme egalitärer vs. konservativer Geschlechtsrollenvorstellungen durch türkische Heranwachsende zu erklären wurden soziodemographische, intergenerationale und interkulturelle Faktoren als unabhängige Variablen in Kovarianzanalysen einbezogen, wobei die Wertvorstellungen der Heranwachsenden als abhängige Variable angesehen wurde. Wie erwartet waren im höhere Maße akkulturierte Heranwachsende was durch die Selbsteinschätzung der Kennt- 
reinforce conservative values in sons. The findings suggest a gendered transmission pattern, where the mother is the direct cultural transmitter and the father exerts influence through normative reference to religious authority. Most importantly, tense intercultural relations are associated with conservative gender-role values among the sons of Turkish migrants.

Key words: acculturation, transmission, gender roles, generations, intercultural relations, discrimination nisse in der deutschen Sprache gemessen wurde - egalitärer eingestellt. Darüber hinaus waren die egalitärsten Wertvorstellungen bei denjenigen Töchtern anzutreffen, die Mütter mit höherer Bildung und egalitären Wertvorstellungen hatten. Umgekehrt verstärkten die väterlichen Ziele im Bereich der religiösen Sozialisation und Diskrimierungswahrnehmungen konservative Wertvorstellungen bei den Söhnen. Die Ergebnisse legen ein geschlechtsspezifisches Transmissionsmuster nahe, bei dem die Mutter die unmittelbare Kulturvermittlerin ist, der Vater aber über die normative Bezugnahme auf religiöse Autorität Einfluss ausübt. Am wichtigste ist jedoch, dass angespannte interkulturelle Beziehungen mit konservativen Geschlechterrollenvorstellungen bei den Söhnen der türkischen Migranten assoziiert sind.

Schlagworte: Akkulturation, Transmission, Geschlechtsrollen, interkulturelle Beziehungen, Diskriminierung

\section{Introduction}

In western European migration contexts, the different and often conflicting values of migrants from majority Muslim countries like Turkey, are at the heart of public and political debates over issues of migration and integration. In particular, Islam is commonly associated with more conservative gender-role values that are at odds with the European host societies' normative commitment to gender equality in the private and public sphere (Phalet \& Hagendoorn, 2002). Yet, cultural norms and values are never static. Especially in a context of migration where different cultures meet, migrant or minority values are subject to acculturative change. Moreover, migrant parents tend to acculturate at a much slower rate than their children, so that intergenerational value discrepancies increase with length of residence in the receiving society (Portes \& MacLeod, 1996; Nguyen \& Williams, 1989; Phinney, Ong \& Maden, 2000). As a consequence, studies comparing migrant and non-migrant families find the largest intergenerational discrepancies between migrant parents and children (Kwak, 2003).

On the one hand, children of migrant parents come to adopt host cultural values, so they tend to endorse traditional family values of interdependence to a lesser extent than their parents (Phinney \& Ong, 2002; Rosenthal, Ranieri \& Klimidis, 1996). On the other hand, however, cross-cultural studies of values have found much evidence of value continuity in migrant families, in particular with regard to traditional 
family values in non-western cultures of relatedness or interdependence (DelgatoGaitan, 1994; Fuligni, Tseng \& Lam, 1999; Greenfield, 1994). This last stream of research suggests that family values of interdependence may resist acculturation and persist in the second generation, in spite of predominant cultural values of independence in Western receiving contexts. Moreover, Nauck (2001) reports more intense intergenerational transmission for core cultural values of relatedness in Turkish migrant families as compared with non-migrant families in Turkey. Apparently, migrant families may be (even) more motivated to pass on core cultural values to the next generation, as they are competing with different and sometimes conflicting host cultural values or role models.

This last finding of more intense value transmission in a migration context hints at the role of intercultural relations in explaining cultural continuity or discontinuity. Interestingly, acculturation studies show that the direction of acculturative change is not predetermined: while acculturative change in the direction of host cultural values and norms is probably the most common finding, the opposite shift away from the host culture may also occur (Berry, 2002). For example, Birman and Trickett (2001) found that Soviet Jewish refugee adolescents identified more strongly with the ethnic culture than their parents. More precisely, evidence of reaffirmation was found for ethnic identity issues, in spite of higher levels of language and behavioural acculturation among adolescents as compared with their parents. Ethnic reaffirmation in the second generation can be understood from the Interactive Acculturation Model (IAM; cf. Bourhis, Moise, Perrault \& Sénécal, 1997). According to Bourhis' Interactive Acculturation Model (IAM), converging and mutually accepting migrant and host acculturation orientations are associated with more harmonious intercultural relations, while diverging orientations are associated with intercultural conflict. More specifically, in relatively exclusionist receiving contexts, where migrants experience more hostility and threat in intercultural relations with hosts, they tend to separate or dissociate from the host culture and instead reaffirm or reinvent the ethnic minority culture and identity as a source of collective self-worth. In turn, migrant acculturation orientations that stress ethnic separation, will further exacerbate hostile reactions from the host society, and aggravate inter-ethnic tension between migrant and host communities (Phalet \& Kosic, in press; Piontkowski, Rohmann \& Florack, 2002; Zagefka \& Brown, 2002; Zick, Wagner, van Dick \& Petzel, 2001). Family values of interdependence play a central role in supporting a sense of collective identity and in-group solidarity in a migration context (Verkuyten, 2001). Therefore, perceived threat in tense intercultural relations may reinforce adolescents' allegiance with traditional family values.

To recapitulate, studies of intergenerational continuity or change in migrant families have reported seemingly contradictory findings of acculturative shifts towards host cultural values, or intergenerational persistence of ethnic cultural values, or even ethnic reaffirmation, or a shift away from the host culture. In light of these diverging findings, our study is concerned with the key question of cultural continuity or change in migrant families. To establish and explain the values of the next generation from a traditional non-western family background, is the overall aim of our study. 
More specifically, this study focuses on gender-role values in Turkish-German migrant families, as one aspect of family relations and obligations. Gender-role values are important for our understanding of acculturative change, because they are at once very central to minority cultures and identities and they are known to differ on average from host cultural values in Western receiving societies. In line with Kağıtçıbaşı's (1996) Model of Family Change (MFC), cross-cultural studies expect and find that gender-role values are becoming more egalitarian with the transition from traditional to modern family models in more socio-economically developed societies (Imamoğlu \& Karakitapoğlu, 1999; Trommsdorff \& Nauck, 2005). According to Kağıtçıbaşı's (1996) MFC, with the decline of material interdependence between family members, the emphasis in modern non-western 'cultures of relatedness' shifts towards emotional forms of interdependence that support personal autonomy rather than rigid paternal authority and that assign equal status to women and men. Thus, the family model of emotional interdependence differs both from a more hierarchical traditional family model and from the prototypical western model of independence. In Turkey for instance, the Value Of Children (VOC) surveys reveal more egalitarian gender roles in younger generations of women, in more highly educated women, in cities and in more recent periods (Kağıtçıbaşı \& Ataca, 2005). However, Kağıtçıbaşı's MFC has not yet been tested in a migration context. Crosscultural trends in family values raise the question whether a similar change towards more egalitarian values can also be found in migrant families who have moved from less developed countries to economically advanced and culturally different western societies. Therefore, our first research question regards the degree and direction of acculturative change in the gender-role values of Turkish-German adolescents as compared with the values of their parents.

The main psychological process that secures some degree of value continuity across generations is the cultural transmission of values within the family (Rohan \& Zanna, 1996; Schönpflug, 2001). In parallel, value continuity or change also depends on acculturation processes in intercultural relations outside the family (Berry, 2002). While intergenerational and intercultural relations jointly shape the values of Turkish-German adolescents, they have mostly been studied separately. Typically, cross-cultural social psychologists have looked for explanations in terms of group processes in intercultural relations whereas developmental psychologists have mostly focused on the role of parents and parenting in intergenerational relations (Grusec, Goodnow \& Kuczynski, 2000; Knafo \& Schwartz, 2001). Our study aims to improve our psychological understanding of value continuity or change among Turkish migrant youth by connecting different explanatory factors from crosscultural social and developmental psychology. Hence our main research question: how do intergenerational relations between parents and children on the one hand, and intercultural relations between migrants and hosts on the other hand, influence the gender-role values of Turkish-German adolescents?"

In what follows, relevant theory and research on cultural transmission, acculturation and gender-role values are briefly reviewed. Next, we argue different hypothetical explanations of the gender-role values of Turkish-German adolescents in more detail. To this end, we combine theory and research explaining value continuity or 
change from two distinct approaches: from intergenerational relations within migrant families and from intercultural relations between migrant and host communities.

\section{Concepts and theory}

\section{Cultural transmission and family values}

The concept of cultural transmission broadly refers to the process of perpetuating the behavioural features of a cultural group through teaching and learning (CavalliSforza \& Feldman, 1981). Transmission is a dynamic process that never leads to a full replication of cultural repertoires from one generation to the next; rather, transmission results in varying degrees of cultural replication and adaptation in a changing environment (Boyd \& Richardson, 1985). A young child learns cultural customs, norms and values mainly through enculturation, which is the largely unreflective and unintentional absorption of the surrounding culture through social modelling, observation and participation in routine cultural practices. This process is complemented by socialisation, which includes the active and purposive teaching of culturally consonant values, norms and behaviours (Berry, Poortinga, Segall \& Dasen, 2002). From an ecological perspective on child development (Bronfenbrenner, 1977), children do not only learn from interactions with their parents within the immediate family context. They also learn from other interactions with peers, adults and institutions outside the family. In a context of migration, cultural transmission within the family is embedded in a surrounding cultural environment that differs from the parents' heritage culture. Following Cavalli-Sforza and Feldman (1981), Berry (et al, 2002) distinguishes between vertical transmission from migrant parents to children from horizontal transmission, which takes place through peer contact within or outside migrant communities. In addition, so-called oblique transmission refers to the influence exerted by adults other than the parents, like teachers, and by institutions other than the family, like schools (Berry et al., 2002). In the case of Turkish migrant families, vertical transmission from parents to children takes place mostly within the context of the ethnic community and culture. In contrast, the contexts of horizontal and oblique transmission are more ethnically mixed and culturally diverse. Whereas vertical transmission is seen to support cultural continuity within migrant families and communities, cultural change enters the family system through informal culture learning in cross-cultural peer contact, through formal education in school, and/or through the adoption of alternative adult role models from the host culture.

Most research on cultural transmission is concerned with the conservation of social or cultural values from one generation to the next (Grusec et al, 2000; Rohan \& Zanna, 1996; Knafo \& Schwartz, 2001; Whitebeck \& Gecas, 1988). Values are defined as abstract desirable goals that become the guiding principles in developing personal attitudes and behaviours (Schwartz, 1992). Not only do values motivate 
culturally consonant personal goals across a wide range of social contexts. Shared cultural values can also confer a sense of collective identity and moral community, which serves to protect personal self-worth and to secure social support. The latter function of cultural values as containers of collective identity and solidarity is most important in migrant or minority groups. To the extent that they support minority identities and loyalties, ethnic cultural values are therefore expected to resist rapid acculturative change (Phalet \& Hagendoorn, 1996; Phalet \& Schönpflug, 2001a).

Family values, in particular, are central to the cultural construction of identity and community. Moreover, they differ significantly across cultures. According to Kağıtçıbaşı's (1996) MFC, cultural differences between predominant western values of separateness and non-western values of relatedness are at the origin of contrasting family models of independence versus interdependence (see also Greenfield, 1994). There are also differences within and between non-western cultures, so that family models in modernizing societies are developing new egalitarian forms of interdependence between family members. As a consequence, low socio-economic development in many non-western cultures is associated with more traditional hierarchical family values. Conversely, socio-economic advancement and educational expansion in modern non-western societies are setting a cross-cultural trend towards more modern egalitarian family values (Inglehart \& Norris, 2003; Trommsdorff \& Nauck, 2005). In line with Kağıtçıbaşı's (1996) MFC, many migrant groups from nonwestern backgrounds come to the West with family values that are far more conservative than host cultural values (Delgato-Gaitan, 1994; Farver, Narang \& Bhadha, 2002; Nauck, 1989; Nguyen \& Williams, 1989; Phalet \& Swyngedouw, 2004; Rosenthal, Bell, Demetriou \& Efklides, 1989). Consequently, the children of migrant parents are confronted with very different traditional non-western versus western family models in the contexts of ethnic and host cultures. Not surprisingly, family values are typically contested as symbolic boundary markers in intercultural relations (Lamont, 2002; Phalet \& Hagendoorn, 2002). And most migrant or minority parents are strongly committed to passing on their visions of family values to their children (Nauck, 2001; Phalet \& Schönpflug, 2001a).

\section{Gender-role values across cultures}

Under the heading of family values, we focus more specifically on gender role values in Turkish migrant families. In this study, the concept and measure of gender role values refers primarily to the equality of men and women, in the sense of equal status for women within the family and equal opportunities in education and employment. Conservative values assign an inferior intra-familial status to the wife, adhere to a traditional family model with a male breadwinner and female caretaker, and stress independence and academic achievement as socialisation goals for boys only. Agreement or disagreement with these views can be ordered along a continuum that opposes conservative gender role values to more egalitarian values.

In general, gender-role values refer to the cultural meaning of gender as distinct from sex. Whereas sex refers to the biological aspects of being female or male, gen- 
der refers to the acquired behavioural and psychological aspects of being male or female (Ashmore, 1990). Biological differences between men and women are at the origin of differential socialisation goals and practices, teaching boys and girls to accept and perform distinct gender roles. However, gender roles are by no means determined or fixed across cultures. On the one hand, cross-cultural research reveals some similar normative ideas about gender and shows that the differences between culturally valued and commonly perceived male and female roles may be very large or very small but that they are hardly ever reversed (Berry et al., 2002). For instance, Williams and Best (1990) found common stereotypes representing men as more assertive and competitive and women as more compliant and caring in 25 countries. Similarly, a study among children in 25 countries found a common tendency to portray women as caring for children and men as occupied in work roles outside the home (Gibbons, Styles \& Shkodriani, 1991).

On the other hand, cross-cultural commonalities leave much room for cultural variation in gender-role values. Thus, Kağıtçıbaşı's (1996) MFC predicts more gender inequality in less developed countries, where traditional family models are centred on material interdependence. Rigid paternal authority in hierarchical relations across generations and across gender characterizes traditional family models. In addition to economic development, cultural meaning systems also make a difference in genderrole values, with most egalitarian values in western 'cultures of separateness', which value independence, as distinct from non-western 'cultures of relatedness', which value interdependence. Accordingly, Trommsdorff and Nauck (2005), who replicated the Value Of Children (VOC) surveys in six non-western cultures, including Turkey, Indonesia, China and Korea, confirm that traditional family systems in less developed countries tend to assign women to an inferior status. Similarly, Inglehart and Norris (2003), analyzing the World Value Surveys (WVS), found that cultures across the globe differ greatly in the extent to which they value gender equality, in the sense of equal rights and opportunities for men and women in their sexual, family and public lives. In addition, they point to the normative role of religion in enforcing conservative gender-role values, in spite of mounting egalitarian pressures with socio-economic development. Most notably, participants in majority Muslim countries were found to espouse the most conservative gender-role values on average, which assign an inferior status to women; in contrast, participants in the historically protestant and largely secularized North-West of Europe were most committed to egalitarian gender-role values; with the other regional and religious country clusters falling somewhere in between.

Looking beyond cultural differences, however, the VOC surveys reveal a significant cross-cultural trend towards more egalitarian gender role values over the last decades and in younger generations of women (Kağıtçıbaşı \& Ataca, 2005; Trommsdorff \& Nauck, 2005). This normative trend confirms the expected shift from traditional to modern family models in cultures of relatedness in Kağıtçıbaşı's (1996) MFC. It coincides with global socio-economic development and educational expansion, so that younger generations of women are more highly educated than their mothers and grandmothers. Interestingly, and in spite of significant and large cultural differences (Inglehart \& Norris, 2003), value change in non-western coun- 
tries is converging with similar trends towards more egalitarian gender role values in Western Europe and in the United States (Thornton \& Young-DeMarco, 2001; Van den Akker, Halman \& De Moor, 1994). In the light of cross-cultural changes in gender role values, as predicted by Kağıtçıbaşı's MFC, the relative persistence of conservative gender role values in many migrant families raises interesting new questions about value transmission and acculturation in a migration context.

\section{Value acculturation in migrant families}

Cross-cultural acculturation studies examine processes of cultural change in intercultural relations between migrants and hosts (Berry, 2002). In another line of research, studies of value transmission have focused mostly on the role of parents and parenting in intergenerational relations. When applied to migrant families, these studies do not usually take on board group processes in intercultural relations as they affect the family system of migrants or minorities (Schönpflug, 2001). Consequently, few studies of migrant families have combined the influences of intercultural and intergenerational relations in the same analysis (see Chun \& Akutsu, 2003; Kwak, 2003).

In acculturation studies, the emphasis has been on value change rather than continuity. Most often, value change is conceived as an acculturative shift in the direction of host cultural values. Change is usually measured by way of mean difference scores that indicate the size of intergenerational discrepancies or 'gaps' between the values and acculturation orientations of parents and children (e.g., Kwak \& Berry, 2001; Phinney \& Ong, 2002; Phinney, Ong \& Maden, 2000; Rick \& Forward, 1992). In the domain of gender role values for instance, Phinney and Flores (2002) found that Hispanics in the United States who have more social contacts with the host society and who are more fluent in English, tend to have more egalitarian attitudes towards gender roles. In addition, generational status, education and gender also make a difference, so that less educated first-generation men hold the most conservative views of gender roles. Most notably, the comparison of first and second generation Hispanics shows the expected acculturative shift towards more egalitarianism in the second generation.

However, the way of measuring value change in acculturation studies does not allow inferences about the strength of intergenerational value transmission within migrant families. As Nauck (1989) pointed out, evidence of aggregate-level value change in acculturation studies has been misinterpreted as indicating the failure of intergenerational transmission in migrant families. A separate strand of crosscultural research on cultural transmission, however, has contradicted this interpretation of intergenerational discrepancies as failed transmission. To the contrary, the few studies that focus on intergenerational transmission in migrant families, have documented significant or even enhanced continuity in the values of migrant parents and their children (Knafo \& Schwartz, 2001; Nauck, 1989; Schönpflug, 2001). In the domain of family values for example, Phalet and Schönpflug (2001a) showed that Turkish family values, which stress interdependence between generations and 
traditional gender roles, are effectively transmitted from Turkish migrant parents to their children. Thus, adolescents whose parents are strongly committed to traditional family values, are themselves more attached to family relatedness than those whose parents are rather weakly committed. Moreover, value transmission is mediated by parental conformity pressure, indicating the goal-directed socialization of traditional family values by migrant parents. More in general, transmission studies estimate the degree of intergenerational value similarity by correlating parental with filial values over parent-child dyads. High correlations indicate successful transmission, which is commonly attributed to the normative impact of parental values and parenting practices in the family context (Cashmore \& Goodnow, 1986; Grusec, Goodnow \& Kuczynski, 2000; Rohan \& Zanna, 1996; Rudy \& Grusec, 2001).

Importantly, mean differences in values in acculturation studies, and correlations of values between generations in transmission studies, carry different information. Technically speaking, strong value transmission can go together with a significant acculturative shift at the aggregate level. Taking together seemingly contradictory evidence from acculturation and transmission research on migrant families, this is indeed what we should expect. In line with findings of effective value transmission, the children of more conservative migrant parents would still be more conservative in their gender roles than children whose parents are less conservative. But regardless of their parents' values and in line with findings of value acculturation, the next generation would move collectively in the direction of more egalitarian gender-role values in the host society. Note that the reverse pattern may also occur: values can be maintained across generations at the aggregate level in the absence of significant transmission from parent to child. This alternative pattern of cultural continuity without vertical transmission is often seen in non-migrant families, where the transmission of cultural values is supported by socializing agents or institutions outside the family. This is why intergenerational discrepancies in non-migrant families may be minor or negligible even in the absence of significant value transmission from parents to children (Nauck, 1989). More in general, parents and children may have similar value orientations without direct transmission from parents to children, because, as a family, they share a common socio-cultural environment and common status attainment (Bengtson, 1975; Bengtson, \& Dunham, 1986).

This study combines elements from both research traditions on acculturation and transmission in migrant families. Its aim is to explain variation and change in the gender-role values of the second generation. To this end, we use data on TurkishGerman families from a major comparative survey among migrant families and youth in Germany (Nauck, 2000). Specifically, the Turkish-German sample consists of $\mathrm{N}=405$ same-sex parent-child dyads, i.e., mother and daughter or father and son, who have answered similar questions about gender-role values. This design allows us to test expectations of value continuity and change derived from studies of value transmission and acculturation. In addition, we replicate value patterns across gender. Furthermore, the survey provides information about the education of the parents and about parenting beliefs and practices. Specifically, migrant parents answered questions about socialisation goals for their son or daughter and about their preferred parenting styles. In addition to the direct effect of parental values, we can there- 
fore test the impact of parents' resources, goals and styles on the values of their children. Finally, adolescents were asked questions about their experiences of acculturation, including language learning, ethnic distance and perceived discrimination, in intercultural relations with German hosts. In this way, we can simultaneously test the impact of intergenerational and intercultural relations on the gender-role values of Turkish-German adolescents. Moreover, the role of intergenerational and intercultural relations is replicated across gender, by comparing value transmission and acculturation in mother-daughter and in father-son relations.

\section{Hypotheses}

\section{Gender and intergenerational discrepancies}

Taking the perspective of the second generation, their gender role values are influenced both by the Turkish heritage culture and by the German host culture. How they negotiate different and sometimes conflicting cultural values with regard to gender roles is the focus of our study. The first Turkish migrants arrived in Germany as guest workers in the 1960s. As a consequence of chain migration, family reunification, and cross-border marriages in the second generation, the Turkish community is currently the largest population of migrant origin in Germany. With respect to gender roles, cross-cultural studies of values show that on average, Turkish migrants and their children are significantly more conservative, or less egalitarian than native Germans (Nauck, 1989). As it is expected from Kağıtçıbaşı's (1996) MFC, value differences between migrant and host communities within Germany are in line with national differences in gender inequality and in gender role values between Turkey and Germany (Inglehart \& Norris, 2003). Also in line with Kağıtçıbaş1's MFC, gender-role values within Turkey are becoming more egalitarian in urban regions, in younger generations of women, and in women with higher education (Imamoğlu \& Karakitapoğlu, 1999; Kağıtçıbaşı \& Ataca, 2005). However, the Turkish migrants in Germany are more likely to be from more rural and less educated strata of the Turkish population, where traditional family values continue to be the norm. Moreover, there is evidence of the relative persistence of conservative family values in Turkish migrant families (Nauck, 1989; Phalet \& Swyngedouw, 2004).

Building on Kağıtçıbaşı's MFC, in cross-cultural studies of values, our first exploratory question regards the degree and direction of value change in Turkish migrant families from one generation to the next. On the one hand, cross-cultural contact in a migration context may cause an acculturative shift in adolescents in the direction of more egalitarian host cultural values, and away from the traditional gender role model of their parents. In line with acculturation studies showing that adolescents acculturate more rapidly than their parents, we therefore expect significant intergenerational discrepancies between Turkish-German adolescents' more egalitarian values and their parents' more traditional values (Hypothesis la). On the other hand, gender role values across cultures are known to differ across gender, 
with women being more egalitarian on average than men (Beutel \& Marini, 1995). Indeed, women's status improves with more egalitarian gender roles while men stand to lose status. In parallel, more conformity pressure is typically exerted on the male side of traditional family systems, since men are expected to take care of their old-aged parents later on and to assume authority over their wives and children (Nauck, 1989; Phalet \& Schönpflug, 2001a). In line with the gendered nature of family values and across generations, therefore, Turkish migrant men tend to be more conservative than women in their value orientations (Phalet \& Swyngedouw, 2004). Accordingly, we expect that the gender-role values of Turkish-German men are more oriented towards conservation, and hence more likely to resist acculturation, as compared with the values of women (Hypothesis $1 \mathrm{~b}$ ).

\section{Intergenerational relations within migrant families}

Most research on cultural transmission is concerned with the vertical transmission of values or norms from parents to children during childhood or adolescence. As the primary transmitters of culture, parents directly influence the values of their children. However, some parental values are more strongly or more effectively transmitted than others. For instance, Turkish migrant parents in the Netherlands successfully transmit traditional family values to their children, including filial obligations and normative gender roles, but not academic achievement values (Phalet \& Schönpflug, 2001b). Since gender-role values are an important part of family values, it is expected that gender-role values are effectively transmitted from parents to children. Therefore, Turkish migrant parents with more egalitarian gender-role values are expected to have children with more egalitarian values (hypothesis 2a). Figure 1 shows the hypothetical influence of parental values and parenting practices on the values of Turkish-German adolescents. All hypothetical explanations will be replicated across gender.

Not only are some parental values more strongly transmitted than others, some parents are also more successful in transmitting their values than others. Indeed, research on value transmission shows that parenting beliefs and practices play an important role in the transmission process (Grusec, Goodnow \& Kuczynski, 2000; Rudy \& Grusec, 2001). In the first place, parenting beliefs and practices directly inform the values of the children. For instance, authoritarian styles of parenting are associated with the socialisation of hierarchical values in a traditional family model (Kağıtçıbaşı, 1996). In addition, it has been suggested that across cultures certain parenting practices support the transmission of values from parents to children, while other practices interfere with the transmission process (Schönpflug, 2001). For example, a lack of warmth or empathy in parenting was associated with reduced intergenerational transmission across value domains (Schönpflug, 2001). This can be understood from Cashmore and Goodnow's (1985) two-process approach of value transmission. According to the two-process approach, effective transmission requires first, that children accurately perceive their parents' values and second, that they willingly accept these values as their own. Parenting beliefs and practices affect 
both processes. For instance, a cold and rejecting parenting style will interfere with the acceptance of parental values by the child, since imposed values are not usually internalised and integrated into a coherent personal value system (Grusec \& Goodnow, 1994; Grusec et al., 2000). Moreover, parenting also affects the accurate perception of parental values, which is required for effective transmission (Cashmore \& Goodnow, 1985; Knafo \& Schwartz, 1992). Since consistency is known to enhance the effective communication of parental values to the child, the use of valuecongruent parenting practices may be particularly powerful in enabling the accurate perception, and hence the transmission of parental values. For example, traditional family values are most effectively conveyed by value-congruent socialisation goals stressing conformity and obedience (Phalet \& Schönpflug, 2001a). To take into account all possible ways in which parenting may impact on adolescents' values, this study not only tests the main effects of parental values and parenting practices on adolescents' values, but it also tests for possible moderator effects of parenting. By moderation we mean that the impact of parental values on the values of their children can be stronger or weaker depending on the corresponding parenting practices.

Two aspects of parenting that have been most extensively researched, are parenting styles and parental goals for their children, or so-called socialisation goals (Levine, Miller \& West, 1988; Schönpflug, 2001). Self-reported parenting styles are known to vary along two distinct dimensions of parental warmth and parental control (Baumrind, 1991; Maccoby \& Martin, 1983). Parental warmth refers to higher or lower levels of acceptance, responsiveness and emotional closeness. Parental control is conceptualised here as being demanding and restrictive with a focus on behavioural compliance (Barber, 1996). Combining both dimensions, an authoritarian style is characterized by higher levels of control and less warmth, as opposed to an indulgent style, which pairs more warmth with lower levels of control (Maccoby \& Martin, 1983). Interestingly, Baumrind (1989) identifies a 'traditional parenting style', which is characterized by a gendered division of tasks, with a distant, authoritarian father and a warm, indulgent mother. In line with the traditional pattern, adolescents in Turkey were more frequently found to perceive indulgent as well as authoritarian parenting (Sümer \& Güngör, 1999). Moreover, a cross-cultural study comparing perceived parenting styles by Turkish migrant and non-migrant youth, confirmed the traditional cultural meaning of paternal authority in Turkish migrant families (Güngör, in press). To examine the role of parenting styles, this study includes measures of self-reported parental warmth and control by father or mother.

Building on Kağıtçıbaşı's (1996) Model of Family Change, we expect that an authoritarian parenting style contributes to the socialization of conservative gender roles, in line with a predominant traditional family model of interdependence among Turkish migrants. Intergenerational relations in the traditional model are characterized by the economic-utilitarian value of children, lifelong material interdependence between parents and children, normative gender roles that assign a low intra-familial status to women, and distant, authoritarian parenting practices that emphasize conformity goals and restrictive control. This traditional model contrasts with a modern family model of emotional interdependence in more developed cultures of relatedness. In the latter model, the emphasis shifts towards the psychological value of 
children, lifelong emotional interdependence in intergenerational relations; increased gender equality; and warm, empathic parenting practices that encourage autonomy goals and emotional closeness. According to Kagitcibasi's distinction between traditional and modern family models therefore, authoritarian parenting (high control) in Turkish migrant families should contribute to the socialization of conservative gender-role values, while empathic parenting (high warmth) would contribute to more egalitarian values (hypothesis $2 b$ ).

Not only parenting styles but also parental socialisation goals contribute to the transmission process (Schönpflug, 2001). In line with Kağıtçıbaşı's (1996) MFC, traditional family systems are characterized by parental goals that stress conformity and obedience in children, as distinct from more modern systems of interdependence, which tend to encourage autonomous agency (Levine et al, 1988). Following up on the cross-cultural finding that there are more conservative gender roles in countries where the population is mostly Muslim (Inglehart \& Norris, 2003), this study focuses on a particular type of conformity goals: those referring to religious authority. Religious socialization goals for children stress conforming their behaviours to religious rituals and rules, and accepting religious authority as a guiding principle in their lives (Meyers, 1996). Across cultures, the role of religion and religious socialisation in maintaining and reinforcing conservative gender-role values has been widely recognized (Inglehart \& Norris, 2003; Kloppenburg \& Hanegraaf, 1995; Sharma, 1987; Van den Akker, Halman \& De Moor, 1994). Therefore, it is expected that religious socialisation goals contribute to the socialization of conservative gender-role values in Turkish migrant families (hypothesis $2 c$ ).

Finally, family-based resources, as indicated by the educational qualifications of the parents, also influence the socialization of values within the family (Bengtson \& Dunham, 1986). Across cultures, the access of women to formal education is directly related to the decline of traditional gender-role values, so that more educated people, and especially more educated women, prefer more egalitarian gender-role values (e.g. Best \& Williams, 1997; Kağıtçıbaşı and Ataca, 2005; Nauck, 1989; Phinney \& Flores, 2002; Trommsdorff \& Nauck, 2005). Not only is the level of education of the parents associated with their own gender-role values, so that parents, and mothers in particular, with higher levels of education have more egalitarian values. But more qualified women are also more able to act upon egalitarian gender-role values than women with less education, which makes them into more consistent and hence more effective role models for their children (Cashmore \& Goodnow, 1985). Moreover, women with a higher educational and occupational status represent more attractive and influential egalitarian models for their children, so that parental education increases both the accuracy of perception and the acceptance of egalitarian values (Cashmore \& Goodnow, 1985). Thus, Schönpflug (2001) showed that the transmission of values from father to son was stronger for more highly educated Turkish migrant fathers. As can be seen in Figure 1, we expect that parental education influences the gender-role values of Turkish-German adolescents both directly and indirectly, through more egalitarian parental values (hypothesis 2d). 
Intercultural relations with the host society

Unlike vertical transmission from migrant parents to their children, horizontal and oblique pathways of transmission refer to interactions with peers, teachers or other adults, who mostly represent host cultural values in a context of migration. Extending Bourhis' (et al., 1997) IAM of migrant-host relations to the explanation of value acculturation, the impact of the host culture on the second generation depends crucially on the quality of intercultural relations between migrant and host communities. If we apply a two-process approach of value transmission to horizontal or oblique pathways of transmission (cf. Cashmore \& Goodnow, 1985), the impact of intercultural relations on the values of the next generation is twofold. Firstly, some degree of cross-cultural contact between migrant and host communities is required for the accurate perception of host cultural values. In addition, migrants or minorities will be more inclined to accept host cultural values, if they experience intercultural relations as friendly or inclusive rather than hostile or exclusive.

Acculturation is the process of socio-cultural change that occurs whenever two or more cultures come into direct and sustained contact (Berry, 2002). This is not necessarily a linear process in which the migrant gradually gives up the heritage culture, and replaces it by the culture of the host society. Rather, it is a bi-dimensional process, in which migrants or minorities combine some degree of ethnic culture maintenance with some degree of cross-cultural contact and participation in the receiving society. The ensuing acculturative changes can take many forms, and value change is one of these (Berry, 2002). Furthermore, the acculturation orientations of migrants and hosts mutually influence each other, so that concordant or discordant migrant and host orientations lead to more harmonious or more conflicting intercultural relations (Bourhis et al., 1997). Conflicting intercultural relations are characterized by maximally diverging and mutually exclusive orientations, so that perceived ethnic prejudice or discrimination from the side of the host society typically reinforces ethnic distance, or a preference for ethnic separation on the side of migrant groups (Piontkowski et al., 2002; Zagefka \& Brown, 2002; Zick et al., 2001).

Building on Bourhis' IAM, it is argued here that value changes in the direction of the host culture are more likely with a higher degree of acculturation and crosscultural contact in the context of a harmonious intercultural relationship. Conversely, ethnic distance and perceived discrimination in hostile or tense intercultural relations will mitigate the normative impact of the host culture. Hence, Turkish-German adolescents who are more competent in, and more oriented towards the receiving culture and society, should have more egalitarian gender-role values (see Figure 1). In contrast, the experience of discrimination in intercultural relations may lead to the ethnic reaffirmation of conservative gender-role values (see Figure 1). In order to assess the experiences of acculturation and intercultural relations among TurkishGerman adolescents, we use measures of German language proficiency, ethnic distance from German culture and society, and perceived discrimination. All hypothetical explanations will be replicated across gender. Below, we argue in more detail the hypothetical effects of intercultural relations on the values of Turkish-German adolescent. 
Most acculturation studies use attitudinal measures to identify the preferences of migrants or minorities for ethnic and/or host cultural values, norms or customs. However, such attitudinal measures are often poor predictors of actual or behavioural acculturation (Van de Vijver \& Phalet, 2004). Therefore, this study includes behavioural as well as attitudinal indicators of the acculturation orientations of Turkish-German adolescents. In the first place, migrants or minorities differ in the degree of behavioural acculturation, as measured by their familiarity with, and competence in the German language and culture. Clearly, a fair degree of behavioural acculturation is required for migrants or minorities to engage in intercultural relations and to fully participate in the host society (Birman \& Trickett, 2001; Jasinskaja-Lahti, 2000). Specifically, language proficiency and language use are key indicators of behavioural acculturation (Birman \& Trickett, 2001; Felix-Ortiz \& Newcomb, 1998; Jasinskaja-Lahti, 2000). As language mastery is the prime prerequisite for cross-cultural contact, it should influence the access of migrants to the host society and its value system. Yet, the evidence of the role of host language acquisition in value acculturation is mixed. Thus, Leaper and Valin (1996) found that English language use was related to gender equality, so that Mexican-American mothers who spoke English at home, report more egalitarian values. However, this was not true for Mexican-American fathers. Likewise, Phinney and Flores (2000), in their study among Hispanic migrants in the US, showed that English language proficiency was associated with egalitarian gender-role values. However, this language effect was no longer significant once migration generation, education, and contacts with non-Hispanic friends were entered into the equation. In the present study, adolescents' self-reported German language proficiency reflects not only their objective competence but also, or maybe mainly, how confident they are about their language skills. More confidence in one's language skills is not only related to higher levels of language mastery but also to more frequent language use. As a measure of behavioural acculturation, therefore, better self-reported German language proficiency should be associated with more egalitarian gender-role values in Turkish-German adolescents (hypothesis 3a).

Looking beyond behavioural or actual acculturation, acculturation attitudes also make a difference. According to Berry's (2002) well-known and extensively validated bi-dimensional acculturation model, the acculturation attitudes of migrants or minorities are organized along two distinct dimensions: ethnic culture maintenance and cross-cultural contact. Combining both dimensions, acculturation attitudes can be categorized into a fourfold typology: integration (high contact, high maintenance), assimilation (high contact, low maintenance), separation (low contact, high maintenance) or marginalization (low on both). For the purpose of explaining the adoption of host cultural values by acculturating adolescents, the contact dimension is clearly the most relevant dimension. Thus, Phinney and Flores (2002) found that minority youth in the US with more cross-ethnic friendships had more egalitarian gender-role values. For the frequency and quality of cross-cultural contacts, both behavioural and attitudinal aspects of acculturation are important. Not only should migrants or minorities be able to engage in cross-cultural interactions with hosts, but they should also be willing to do so. Therefore, the rejection of cross-cultural con- 
tact in a separation type of acculturation is expected to interfere with value acculturation in the direction of the host culture. In contrast, integration or assimilation types of acculturation, which favour cross-cultural contact with the host society and culture, should enhance value acculturation. Accordingly, in their study of value acculturation among Turkish migrants, Phalet and Swyngedouw (2004) found that migrants who were more oriented towards separation from the host culture, had more conservative values than those who were more oriented towards integration or assimilation. In the present study, we used three indicators of ethnic distance as measures of negative attitudes towards cross-cultural contact in a separation type of acculturation: firstly, the rejection of a German marriage partner, secondly, the rejection of German names for one's children, and lastly, one's future return plans to Turkey. In line with previous findings of value acculturation, it was expected that Turkish-German adolescents who are more separated, in terms of ethnic distancing from the German host culture, have more conservative gender-role values (hypothesis $3 b$ ).

Figure 1. Hypothetical model: Expected effects of intergenerational and intercultural relations on the gender role values (GRV) of TurkishGerman adolescents

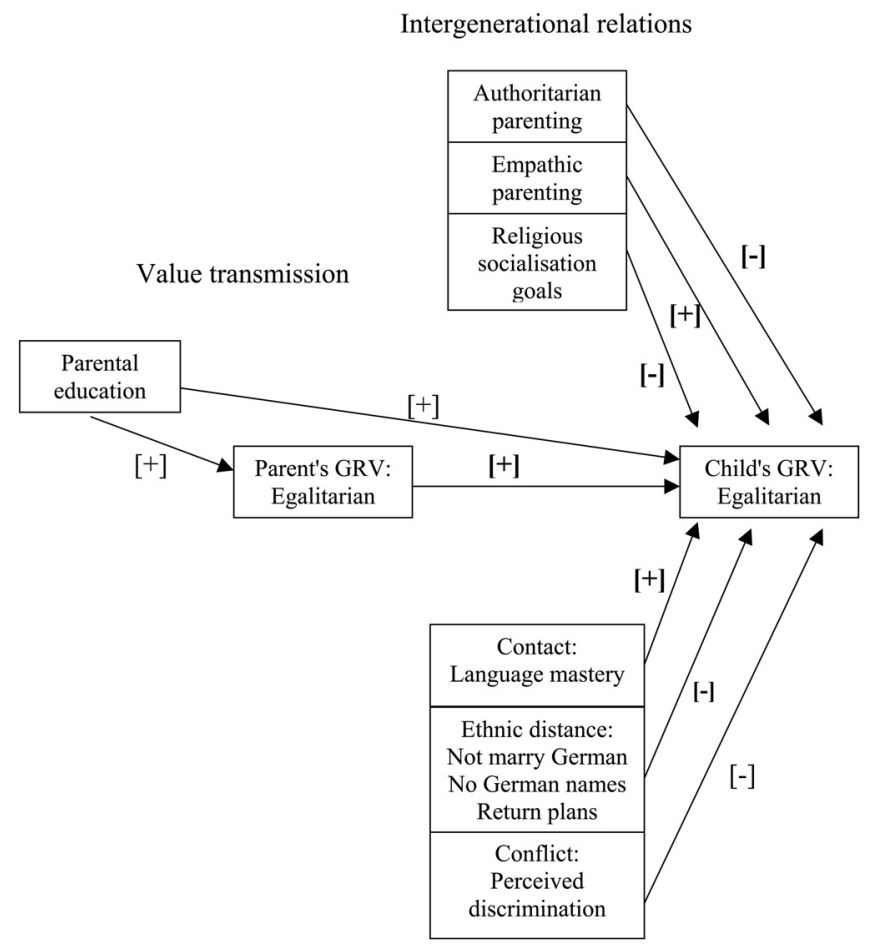

Intercultural relations 
Finally, acculturation is a two-way process (Bourhis et al., 1997). From an interactive perspective, the frequency and quality of cross-cultural contact required to achieve value acculturation does not only depend on the orientations and skills of migrants. It also depends on the degree to which migrants are accepted and included by dominant groups and institutions in the host society. For example, Nauck (2001) found that higher levels of perceived discrimination are related to less inter-ethnic contacts in the social networks of Turkish migrants. Similarly, perceptions of discrimination in intercultural relations have been related to reactive ethnic identification and ethnic reaffirmation among minority youth (Andriessen, 2006; Branscombe, Schmitt \& Harvey, 1999). In this study, perceived discrimination is measured at the personal level and in different social contexts, such as the school, shops and the neighbourhood. In accordance with Bourhis' (et al., 1997) Interactive Acculturation Model (IAM), we expect more conservative gender-role values among TurkishGerman adolescents who perceive more ethnic discrimination (hypothesis 3c).

\section{Method}

\section{Samples and measures}

The data used to test our hypotheses were gathered as part of a major survey among migrant families in Germany (Nauck, 2000). The sampling design couples adolescents with their parents in same-sex parent-child dyads, i.e. fathers with sons and mothers with daughters. The Turkish migrant sample consists of 205 Turkish fathers and their sons, and 200 Turkish mothers and their daughters $(\mathrm{N}=405)$. Turkish migrant families were sampled in Berlin and in the Lake Constance (Bodensee) region in the South of Germany. The parents are first-generation migrants who were born in Turkey and who were mostly attracted as guest workers by the German government and industries in the early 1970s. The average age of the fathers was 45 years and that of the mothers 41 years. The average age of their children was fifteen years. Of the children, $80 \%$ were born in Germany, and most others arrived in Germany in early childhood. Since all children attended primary school in Germany, they are considered here as second generation. At the time of the survey, they were in grades seven to nine of secondary school, with $54 \%$ attending lower vocational tracks. While the higher streams in the German school system prepare students for higher education, lower vocational tracks prepare students to make the transition to the labour market. Most Turkish migrant parents, and women in particular, had low levels of education. Of the fathers, $8 \%$ had no formal qualifications, $59 \%$ had primary, $29 \%$ full secondary, and $4 \%$ tertiary qualifications. Of the mothers, one in three or $34 \%$ had no formal qualifications, $46 \%$ had only primary, $17 \%$ full secondary, and $3 \%$ tertiary qualifications.

In a first step of the data collection procedure, adolescents filled out paper-andpencil questionnaires in German in school. In order to minimise social or situational sources of correlation between generations, parents and children were approached 
separately, in different contexts, and most often in different languages. Thus, in a next step, parents were contacted by co-ethnic interviewers at their homes for standardized face-to-face interviews in the language of their choice (i.e., Turkish or German).

As measures of gender-role values, parenting and acculturation, the parent and child questionnaires include the following questions and scales.

Gender-role values. A short version of the Sex Role Orientations (SRO) scale (Brogan \& Kutner, 1976; Krampen, 1983) was used to measure gender-role values in parents and children. Principal Component Analysis yields one factor opposing more egalitarian to more conservative gender role values, which explains $45.5 \%$ of the variance for children and $45.4 \%$ for parents. The following five items loaded on this factor: 'In case of disagreement between husband and wife, the husband should always decide' (reversed), 'A husband's task is to earn money; a wife's task is to look after the home and the family' (reversed), 'The education of boys should be more important for teachers and parents than that of girls' (reversed), 'Girls should be allowed to learn the same occupations as boys', and 'Parents should encourage independent behaviour in their daughters as well as in sons'. The items form an internally consistent composite scale ( $\alpha=.70$ for children and .69 for parents). Response categories are recoded from (1) fully disagree to (4) fully agree, so that lower scores indicate more conservative gender-role values and higher scores more egalitarian values.

Religious socialisation goals. The self-reported religious socialisation goals by parents were assessed with the following three statements: 'My child should obey the teachings of the Quran', 'My child should learn a lot about the mosque and the faith when he/she is still young' 'My child should visit the mosque weekly'. The items form a reliable composite scale $(\alpha=.87)$. Response categories are recoded from (1) fully disagree to (4) fully agree. Hence, a lower score indicates that less importance is attached to the religious socialization of the child, and a higher score indicates that religious socialization is more important.

Parenting styles. To assess distinct warmth and control dimensions of self-reported parenting styles, Nauck and Schönpflug (1997) developed cross-cultural measures of empathic parenting (i.e., warmth or indulgence) and authoritarian parenting (i.e., restrictive control). Principal Component Analysis with Varimax rotation yields the expected two-factor solution for authoritarian and empathic styles of parenting, with the former explaining $30 \%$ of the variance and the latter an additional $23 \%$. Five items measure authoritarian parenting: 'Under no circumstances do I permit my child to contradict me', 'If my child says something that does not please me, I get very upset', 'If my child has been assigned a task, I do not allow him (her) to give up until (s)he has completed the task', 'I never tolerate that my child deviates even slightly from my orders', 'When there is a problem I listen to what my child has to say, but in the end I always decide alone'. These five items form a reasonably internally consistent composite scale $(\alpha=.68)$, with response categories recoded from (1) fully disagree to (4) fully agree. Hence, higher scores indicate more authoritarian 
parents. In addition, three items measure empathic parenting: 'I know immediately when my child likes something very much just by looking at him (her)', 'When I see my child, I can guess without words if he (she) is sad', When I see him (her), I can feel when something is wrong with my child'. Together, these statements form a fairly internally consistent composite scale $(\alpha=.66)$, with higher scores indicating more empathic parenting. It should be noted, however, that the distribution is very skewed, because many Turkish migrant parents fully agree with all three statements.

Parents' education. The education of the parents was coded into five categories, from (1) no qualifications, (2) primary school, (3) lower secondary, and (4) full secondary; up to (5) university degree.

German language proficiency Four questions measure the self-reported German language proficiency by adolescents, who rated their ability to understand, speak, read and write German. The four ratings form a reliable composite scale $(\alpha=.84)$. Response categories were (1) little or no mastery, (2) good, or (3) very good, so that higher scores indicate higher levels of language proficiency.

Ethnic distance. Ethnic distance from the German host society and culture was measured by three separate questions. The first question concerns the rejection by adolescents of a German marriage partner: 'Can you imagine that one day you will marry a German (wo)man?' with response categories (3) certainly not, (2) possibly, and (1) probably. Note that a significant portion of adolescents who do not want to marry, are treated as missing. The next question regards the rejection of German names for children: 'Suppose you would have children in Germany, which names would you give to your children? with response categories (3) Turkish names, (2) Turkish names that are easy to pronounce in German, or (1) German names. Adolescents who prefer other international names are treated as missing. Lastly, adolescents were asked about future return plans to Turkey: 'When you grow up, do you want to (3) return to Turkey, or (1) stay in Germany, or are you (2) undecided? Those who want to emigrate to a country other than Turkey are treated as missing. The three questions about partner choice, name giving and return plans are used here as single indicators of ethnic distance, since they do not form a consistent composite scale.

Perceived discrimination. Adolescents' perceptions of discrimination were measured at the personal level. Specifically, they answered three questions about the extent to which they personally experienced unfair treatment or discrimination in school, in the neighbourhood where they live, and when shopping. These three questions form an internally consistent composite scale $(\alpha=.68)$. Response categories were recoded from (1) fully disagree to (4) fully agree, so that a high score indicates high levels of perceived personal discrimination. 


\section{Results}

\section{Value discrepancies}

Table 1 shows descriptive statistics (means and standard deviations) for all concepts and measures across gender, including values, parenting, education, acculturation and perceived discrimination. In addition, Figure 2 represents the observed discrepancies in gender role values across generations and across gender.

Table 1. Measures of Gender Role Values (GRV), parenting, education, acculturation and perceived discrimination: Means, standard deviations and differences between male and female dyads

\begin{tabular}{|c|c|c|c|c|c|}
\hline & \multicolumn{2}{|c|}{ Male dyads: } & \multicolumn{2}{|c|}{ Female dyads: } & \multirow{2}{*}{$\begin{array}{c}\begin{array}{c}\text { Gender } \\
\text { difference: }\end{array} \\
\text { T-value }\end{array}$} \\
\hline & Mean & SD & Mean & SD & \\
\hline $\begin{array}{l}\text { Child's Gender-Role Values } \\
\text { Parent's Gender-Role Values } \\
\text { Parental education (parent) }\end{array}$ & $\begin{array}{l}2.82 \\
2.91 \\
2.50\end{array}$ & $\begin{array}{r}.63 \\
.67 \\
1.00\end{array}$ & $\begin{array}{l}3.11 \\
3.01 \\
1.97\end{array}$ & $\begin{array}{l}.65 \\
.71 \\
.97\end{array}$ & $\begin{array}{l}-4.68^{\star * *} \\
-1.30 \\
5.44^{\star * *}\end{array}$ \\
\hline $\begin{array}{l}\text { Parenting (parent ): } \\
\text { - religious socialisation goals } \\
\text { - authoritarian parenting } \\
\text { - empathic parenting }\end{array}$ & $\begin{array}{l}2.93 \\
2.99 \\
3.43\end{array}$ & $\begin{array}{l}.95 \\
.67 \\
.64\end{array}$ & $\begin{array}{l}2.65 \\
2.82 \\
3.68\end{array}$ & $\begin{array}{r}1.04 \\
.68 \\
.48\end{array}$ & $\begin{array}{l}2.82^{\star *} \\
2.53^{*} \\
-4.59^{\star * *}\end{array}$ \\
\hline $\begin{array}{l}\text { Acculturation (child): } \\
\text { - German language mastery } \\
\text { - not marry German partner } \\
\text { - no German name for child } \\
\text { - future return plans }\end{array}$ & $\begin{array}{l}2.42 \\
1.41 \\
1.48 \\
2.26\end{array}$ & $\begin{array}{l}.51 \\
.57 \\
.90 \\
.73\end{array}$ & $\begin{array}{l}2.48 \\
1.53 \\
1.27 \\
2.22\end{array}$ & $\begin{array}{r}.42 \\
.55 \\
1.19 \\
.80\end{array}$ & $\begin{array}{r}-.63 \\
-1.61 \\
2.1^{*} \\
.09\end{array}$ \\
\hline perceived discrimination (child) & 1.46 & .56 & 1.38 & .54 & .26 \\
\hline
\end{tabular}

$* \mathrm{p}<.05 * * \mathrm{p}<.01 * * * \mathrm{p}<.001$

Across generations and gender, Turkish migrant families tend to disagree in part with conservative gender role values. There are also significant differences along the generation and gender divides. As can be seen from Figure 2, intergenerational discrepancies between migrant parents and their children are significant for mothers and daughters only (paired-samples t-value $=2.06 ; \underline{p}<.05$ ). Turkish-German daughters have more egalitarian gender role values than their mothers. In contrast, sons have rather more conservative values than their fathers, but this difference is not significant. Looking across gender, value differences between fathers and mothers are not significant either. But sons are significantly more conservative (or less egalitarian) than daughters ( $\underline{\mathrm{t}}$-value $=-4.68 ; \underline{\mathrm{p}}<.001$ ). This pattern suggests an acculturative shift among Turkish-German women towards more egalitarian values. As a consequence, we find evidence of a 'generation gap' between migrant mothers and daughters, but not between migrant fathers and sons. At the same time, the diverging gender role values of daughters are at the origin of an emerging gender gap in the second generation, opposing more egalitarian women to more conservative men. 
Figure 2. Intergenerational discrepancies in Gender Role Values (GRV) in Turkish migrant families: Father-son and mother-daughter dyads

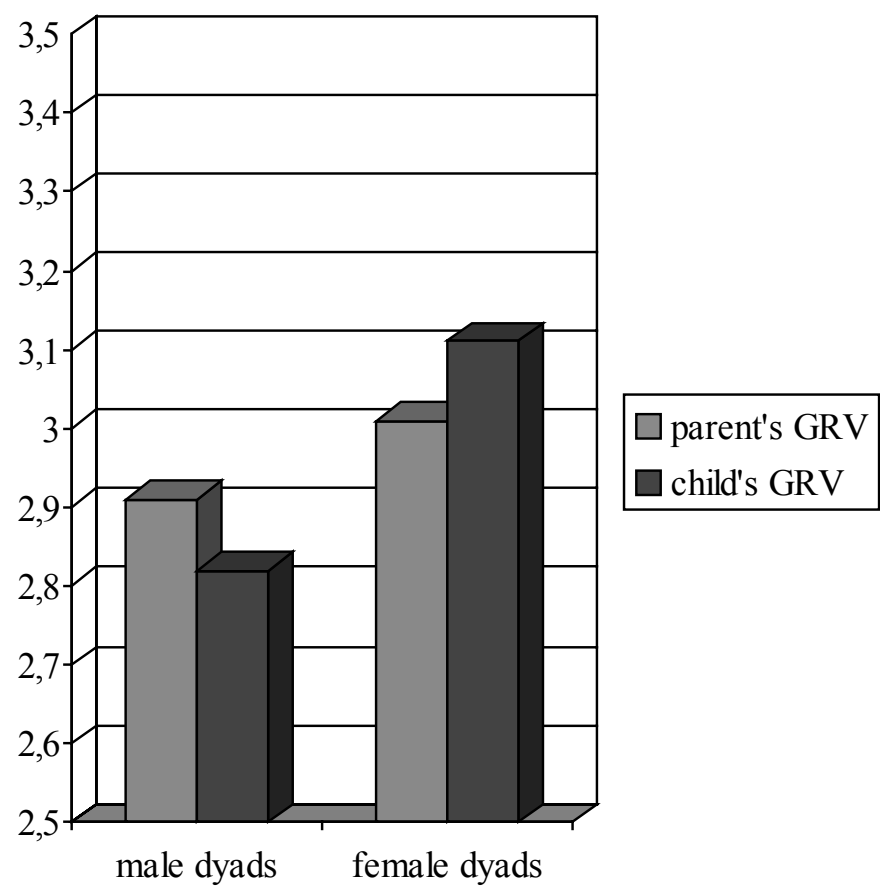

Turning to parenting, we find that Turkish migrant parents on average tend to agree with religious socialization goals and with authoritarian parenting. At the same time, most of them fully agree with empathic parenting. Overall, this pattern is in line with a traditional 'authoritarian-indulgent' parenting style, which combines restrictive control with emotional closeness (Baumrind, 1989), and which is also common in Turkey (Sümer \& Güngör, 1999). But the parenting profiles of migrant mothers and fathers also differ. Fathers attach more importance to religious socialization $(\underline{\mathrm{t}}=$ $2.82 ; \underline{\mathrm{p}}<.01)$; and they are more authoritarian $(\underline{\mathrm{t}}=2.53 ; \underline{\mathrm{p}}<.05)$. Mothers, in contrast, are much more empathic in their parenting styles $(\underline{\mathrm{t}}=-4.59 ; \underline{\mathrm{p}}<.001)$. The gendered nature of the parenting profiles is in accordance with Baumrind's (1989) notion of a traditional parenting style, which combines a distant, authoritarian father with a warm, indulgent mother. Moreover, a recent study of perceived parenting styles confirms the persistence of authoritarian paternal control in Turkish migrant families (Güngör, in press). Furthermore, our data suggest that the nature of religious socialization in Turkish-German families is gendered, in that religious authority is linked to paternal authority or control in traditional family systems.

Lastly, Turkish-German adolescents rate their language skills in German as good to very good, but they would rather not marry a German partner nor give German 
names to their children. Moreover, they have not yet decided if they will stay in Germany or return to Turkey in the future. Finally, daughters and sons do not differ significantly in their levels of acculturation and perceived discrimination, with one exception: Turkish-German girls are slightly less averse of German names for their children than boys.

\section{Value transmission and acculturation}

In a next step, children's values were entered as dependent variables in Analyses of Covariance (ANCOVA) taking the parents' education, values and parenting practices and the children's acculturation and perceived discrimination as independent variables. The model was tested separately for father-son dyads and for motherdaughter dyads (see Figure 3). In addition to the hypothesized main effects of parental education and parenting practices, interaction effects with parental values were also tested (cf. supra). To this end, both covariates were centred and their crossproduct was added to the analysis (Aiken \& West, 1991). The total explained variance ( $\underline{\mathrm{R}}$ squared) in adolescents' gender-role values was $16.9 \%$ in father-son dyads and $19.4 \%$ in mother-daughter dyads.

In father-son dyads, no significant direct transmission of values was found from father to son. Interestingly, there was also no significant intergenerational discrepancy between the values of Turkish migrant fathers and sons. Together, these findings suggest intergenerational continuity of conservative gender-role values on the male side of Turkish migrant families, in the absence of direct value transmission from father to son. Nevertheless, intergenerational relations do make a difference in the gender-role values of the sons. Specifically, the fathers' religious socialisation goals have a predicted effect on the gender-role values of their sons $(\mathrm{F}(1,185)=$ $8.03 ; \underline{p}<.01, \beta=-.16$ ). The more Turkish migrant fathers stress religious conformity as an important socialisation goal for their sons, the more conservative the genderrole values of their sons are (see Figure 3). Intercultural relations also play a role. As expected, a son's self-reported language proficiency is significantly related to his gender-role values $(\underline{\mathrm{F}}(1,185)=12.48 ; \mathrm{p}<.01 ; \beta=.29)$. In sons, higher levels of German language mastery go together with more egalitarian gender-role values (see Figure 3). Finally, there is a significant main effect of perceived discrimination on the gender-role values of the sons $(\underline{F}(1,182)=3.99 ; \underline{p}<.05 ; \beta=-.17)$. As expected, the more discrimination the son encounters, the more conservative are his genderrole values (see Figure 3). No other main or interaction effects on adolescent values are significant in father-son dyads. 
Figure 3. Effects of intergenerational and intercultural relations on the gender role values (GRV) of Turkish-German adolescents: Standardized regression coefficients for mother-daughter and father-son dyads

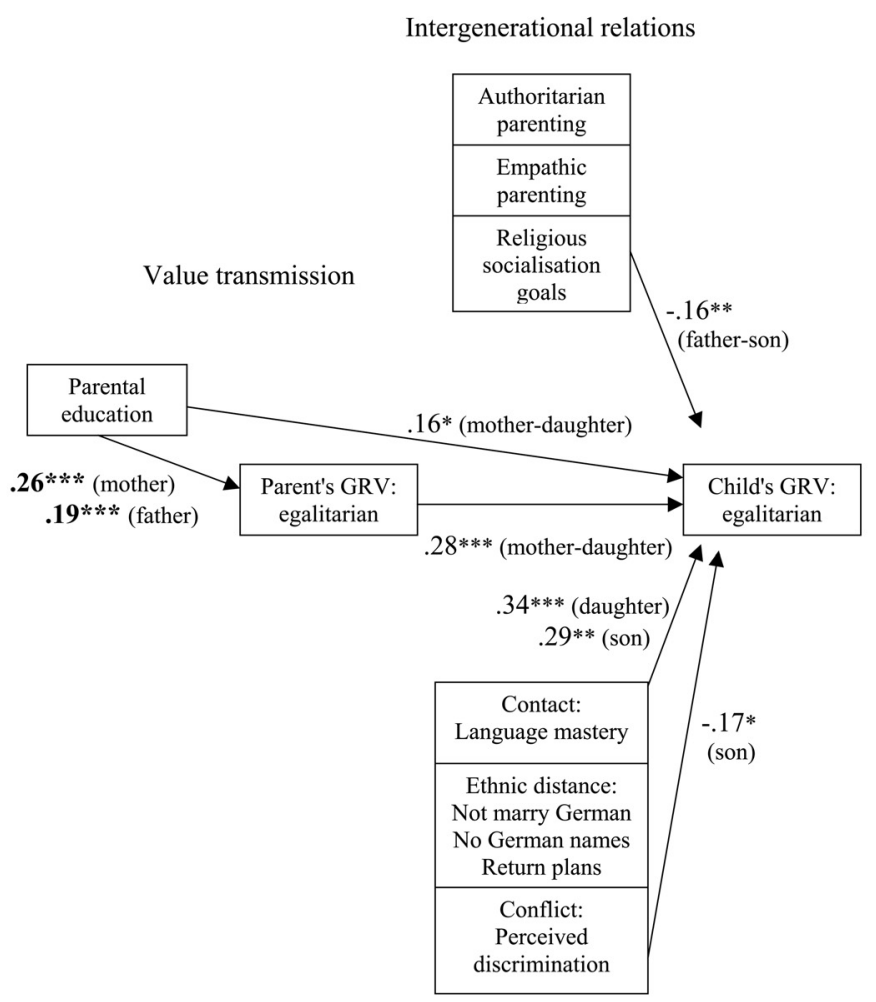

Intercultural relations

In mother-daughter dyads, we did find the significant direct transmission of genderrole values from mothers to daughters $(\underline{\mathrm{F}}(1,191)=16.56 ; \underline{\mathrm{p}}<.001 ; \beta=.28)$. As expected, the more egalitarian the gender-role values of the mother, the more egalitarian are the values of her daughter. At the same time, as a result of horizontal or oblique transmission, we saw that the daughters were also more egalitarian than their mothers. Apparently, Turkish migrant mothers effectively transmit their gender-role values in spite of value discrepancies between mothers and daughters. Note that this pattern of adaptive value change in the presence of effective vertical transmission from mother to daughter is the opposite of the male pattern of cultural conservation without vertical transmission from father to son (cf. supra). In addition and in line with expectations, the level of education of mothers has significant direct as well as indirect effects on their daughters' gender-role values. Thus, maternal education directly impacts on the values of the next generation, in that daughters of more highly educated mothers, hold more egalitarian family values $(\underline{\mathrm{F}}(1,191)=3.40 ; \underline{\mathrm{p}}<.05$; 
$\beta=.16$ ). Post hoc comparison of means indicates that this effect is seen at the transition to full secondary or higher education: mothers with at least full secondary education have more egalitarian daughters than mothers with lower levels of education. In addition, the education of the mother also influences the gender-role values of her daughter indirectly, through the more egalitarian values of more highly educated mothers. A separate ANOVA was performed to test the effect of parents' educational level on their own gender-role values. Across gender, parental education was a significant predictor of parents' gender-role values $(\mathrm{F}(4,200)=9.54 ; \underline{\mathrm{p}}<$ $.001 ; \beta=.26$ for mothers; $\underline{\mathrm{F}}(4,205)=6.75 ; \underline{\mathrm{p}}<.001 ; \beta=.19$ for fathers). This means that parents with higher education have more egalitarian gender-role values. However, this only affects the children's values in female dyads, since no significant value transmission takes place in male dyads. Finally, also for daughters, intercultural relations make a difference in the adoption of host cultural values. As expected, the self-reported German language proficiency by daughters had a significant effect on their gender-role values $(\underline{\mathrm{F}}(1,191)=14.42 ; \mathrm{p}<.001 ; \beta=.34)$. As Figure 3 shows, the higher the self-reported level of the German language mastery of adolescents, the more egalitarian are their gender-role values. This effect of language acculturation is fully replicated across gender. No other main or interaction effects are significant in mother-daughter dyads.

\section{Discussion}

Most Turkish migrants, who have been recruited from the more conservative, rural and less educated segments of the Turkish population, brought along their traditional family values, which assign inferior status to women (Kağıtçıbaşı \& Ataca, 2005; Nauck, 1989). As a consequence, the children of Turkish migrants are confronted with very different host cultural values, which favour more egalitarian gender roles as part of a western family model of independence (Kağıtçıbaşı, 1996). In light of the known cultural differences between ethnic and host cultural values pertaining to normative gender roles, this study is aimed at improving our understanding of the gender-role values of Turkish-German adolescents, and how they are simultaneously shaped by intergenerational relations within migrant families on the one hand, and by intercultural relations with German hosts on the other hand. Below, we briefly discuss the most important findings and their theoretical implications. We conclude by identifying some limitations in the data and the analysis, and some pointers for future research on value transmission and acculturation in migrant families.

\section{Intergenerational discrepancies}

Previous studies of value acculturation in migrant families revealed seemingly contradictory findings of cultural continuity and change in the second generation. Al- 
though most studies find an intergenerational shift in the direction of host cultural values (e.g., Kwak, 2003), value acculturation is not a linear process. Thus, there is some evidence of effective or even enhanced value transmission from migrant parents to children (e.g., Knafo \& Schwartz, 2001). Likewise, other findings document a reverse tendency towards ethnic reaffirmation, or an intergenerational shift away from the host culture (Birman \& Trickett, 2001). Against the background of these conflicting findings, the first aim of this study was to establish intergenerational discrepancies in Turkish migrant families in the domain of gender-role values. Drawing on cross-cultural expectations and findings of value differences across generations and gender, we hypothesized that adolescents would be more egalitarian on average in their gender-role values than their parents (Hypothesis 1a), and that women would be more egalitarian than men (Hypothesis 1b). Our findings confirm both hypotheses, though only in part.

Most importantly, on the female side of Turkish migrant families, we find the expected value discrepancies between more traditional mothers and more egalitarian daughters. This acculturative shift towards more egalitarian values for daughters is in line with earlier findings of a slower rate of value acculturation in the first generation as compared with the second generation (e.g., Phinney \& Vedder, in press). Moreover, the direction of value change suggests that Kağıtçıbaşı's (1996) Model of Family Change (MFC) can to some extent be generalized to Turkish migrant families. As distinct from Turkish families in Turkey, Turkish migrant families are directly exposed to egalitarian values as part of a culturally different family model of independence in the host society. According to Kağıtçıbaşı's MFC, socio-economic advancement and educational opportunities in the receiving society should be accompanied by the transition from traditional to modern family models of interdependence, which assign more equal status to women. However, Kağıtçıbaşı's MFC is confirmed only in part. Contrary to our first hypothesis, no significant intergenerational discrepancies were found on the male side of Turkish migrant families. If anything, the gender role values of the sons are rather more conservative than the values of Turkish migrant fathers, although this difference is not significant. Moreover, looking across gender and generations, the average profile of Turkish migrant families seems closest to a traditional family model. More precisely, the average Turkish migrant family was characterized by moderately conservative genderrole values, a strong emphasis on religious conformity, and a traditional authoritarian-indulgent parenting style (cf. Baumrind, 1989).

At the same time, we find the expected gender difference between the values of more egalitarian daughters and more conservative sons. As a consequence of the gendered nature of traditional family systems, there is more conformity pressure on sons, who are expected to take care of their old-aged parents in the future. Moreover, women have most to gain from egalitarian gender role values, in terms of equal status, opportunities and rights. Consequently, the egalitarian shift of the daughters of Turkish migrants is at the origin of a new gender gap in the second generation. Indeed, Turkish migrant mothers and fathers did not significantly differ in their gender role values, but their daughters and sons do. Most notably, more egalitarian second-generation women differ both from their mothers and from their brothers. 
In sum, the picture of Turkish migrant families that emerges from our data is that of a traditional family model under pressure, due to the acculturative shift of daughters towards more egalitarian values in the host society. The theoretical question is whether value discrepancies in Turkish migrant families signify the transition towards a modern family model of interdependence, in line with Kagitcibasi's (1996) MFC, or whether the next generation will be caught in a culture clash between the conservation of tradition and western values of independence.

\section{Intergenerational relations and value transmission}

How to explain the intergenerational change towards more egalitarian gender role values in women, in combination with the persistence of conservative values in men? Taking an intergenerational perspective on value transmission, cross-cultural psychologists have identified parental values and parenting practices as the primary sources of cultural continuity in family values (e.g., Rohan \& Zanna, 1986). Indeed, traditional family values in migrant families appear to be effectively transmitted from one generation to the next (e.g., Knafo \& Schwartz, 2001). In the domain of gender-role values, therefore, we expected that the children of more conservative parents would themselves have more conservative values than children whose parents were less conservative (Hypothesis 2a). In addition, we hypothesised that parenting practices would also contribute to adolescents' gender-role values. In line with cross-cultural findings and with Kağıtçıbaşı's (1996) MFC, more authoritarian parents and parents who stress religious socialisation goals more, should reinforce conservative gender-role values in their children, as opposed to more empathic, less authoritarian, and/or less religious parents (Hypothesis $2 b$ and $c$ ). Finally, parental resources, as indicated by their formal qualifications, are crucial preceding variables that impact on the intergenerational transmission of values. Thus, the children of parents with higher levels of education were expected to have more egalitarian genderrole values (Hypothesis $2 d$ ).

Turning to our findings, distinct patterns of transmission were found for male and female dyads. In line with the second hypothesis, the gender-role values of the mother are directly transmitted to the daughter: more egalitarian mothers have more egalitarian daughters, and vice-versa, more conservative mothers have more conservative daughters. But there is no significant value transmission from father to son. Since the vertical transmission of gender-role values is situated on the female side of Turkish migrant families, our second hypothesis is confirmed only in part. In addition to the vertical transmission of traditional values from migrant parents to their children, the horizontal or oblique transmission of host cultural values also contributes to adolescents' own values. Indeed, and in line with our first hypothesis, effective value transmission from mothers to daughters goes together with adaptive change towards more egalitarian values in the host society in daughters. This pattern is in accordance with the more general nature of cultural transmission, which secures some measure of cultural continuity while allowing for adaptive changes to a changing socio-cultural environment from one generation to the next (Berry et al., 
2002). Interestingly, exactly the opposite pattern applies to the male side of Turkish migrant families, where conservative gender-role values resist acculturative change and persist into the next generation. Moreover, cultural continuity is achieved in the absence of direct intergenerational transmission from father to son within migrant families.

How is this unexpected finding of a gendered pattern of value transmission in Turkish migrant families best understood? One line of reasoning starts from the gendered nature of intergenerational transmission. Whereas mothers act as the primary socialising agents who pass on their own personal values in emotionally close relationships with their children, fathers represent a less personal and more distant normative authority within the traditional family system. This argument receives rather indirect support from observed gender differences in parenting within Turkish migrant families: in line with a traditional family model, we find more authoritarian control and more religious conformity pressure in Turkish migrant fathers, and more empathic parenting in mothers. This division of parental tasks confirms earlier findings of what Baumrind (1989) has called a traditional parenting style, where rigid paternal control is counterbalanced by maternal warmth or indulgence (Sümer \& Güngör, 1999; Güngör, in press). The traditional gendered pattern of male authority and conformity pressure has been explained by the old-age security value of sons, who are expected to look after their parents in old age (Kagitcibasi, 1996). From what we know about the role of parenting in the transmission of values (cf. Rohan \& Zanna, 1996; Rudy \& Grusec, 2001), it is not surprising that the gendered parenting pattern should affect the transmission of values in Turkish migrant families. On the female side, high levels of empathy and emotional closeness are known to foster the communication and acceptance of parental values, while simultaneously allowing for adaptive value change as a consequence of acculturation. On the male side, in contrast, rigid paternal control may interfere with the personal transmission of values from father to son, while at the same time reinforcing the collective compliance of the next generation with traditional family values and gender roles. Finally, a rather different line of reasoning refers to gender differences in acculturation processes in order to explain gender differences in value acculturation. This argument will be developed further in the next paragraph under the heading of intercultural relations.

Returning to the role of intergenerational relations, we find that the hypothesized role of parenting is again partly confirmed by our findings. As expected fathers who stress religious socialisation goals more, have more conservative sons. Interestingly, the same is not true of mothers and daughters. Again, we refer to the gendered parenting pattern in traditional family systems as a possible explanation. We saw that religious conformity pressure is mostly exerted by fathers and not by mothers. Clearly, the reference to religious authority is part of the cultural meaning of paternal authority in Turkish migrant families. In line with cross-cultural findings on religion and gender equality, the religious socialisation of sons effectively reinforces conservative gender role values. However, no additional significant effects of parenting styles were found at the individual level. Still, the hypothetical association of parenting styles with gender-role values receives indirect support from gender differences 
in adolescents' values. Thus, more conservative gender-role values in son are in line with the expected conservative impact of a more authoritarian and distant parenting style in Turkish migrant fathers. Conversely, a more lenient and warm parenting style in mothers goes together with more egalitarian values in daughters. The fact that parenting makes no significant difference within gender, however, may point to data limitations as well as conceptual problems. In particular, empathic parenting is so strongly endorsed by Turkish migrant parents that a ceiling effect may have suppressed its correlation with adolescents' values. Apparently, a rather strong normative consensus around a traditional parenting style in Turkish migrant families implies that there is little individual variation beyond a significant gender difference between more authoritarian fathers and more indulgent mothers. Furthermore, our measure of authoritarian parenting captures a restrictive form of parental control, which would interfere with the internalisation of values by children. Moreover, cross-cultural studies do not agree about the meaning and impact of parental control in the socialisation of values: although some degree of control is required, too much control or too rigid a form of control may actually hinder the transmission of values (Schönpflug, 2001). It should be added that the cultural meaning of paternal control especially depends on social representations of normative authority (Güngör, in press). To throw more light on the role of migrant fathers in the transmission of values, therefore, we would need more refined measures of different (e.g., behavioural and psychological) aspects of control in their cultural context.

Finally, we expected and found that education is crucial in enabling the socialisation of egalitarian gender-role values. One way in which education influences the values of the next generation is mediated through parents' own values. Thus, parents who have at least completed full secondary education are more in favour of gender equality. And this egalitarian effect of education is even stronger for women than for men (Beutel \& Marini, 1995; Trommsdorff \& Nauck, 2005). Our hypothesis was only partly confirmed, however, since only mothers effectively transmit their own gender-role values to their children. In addition, parental education also contributes directly to more egalitarian gender-role values in the next generation. Again, this direct effect is limited to mothers and daughters. It seems that more highly educated mothers are more influential egalitarian role models for their daughters than mothers with less education. We reasoned that highly qualified mothers are most likely to be both capable and committed to successfully applying egalitarian gender-role values in their own professional and family life. Thus, they provide their daughters with a most consistent and attractive female role model. In line with a two-process approach of value transmission (Cashmore \& Goodnow, 1985), we argued that educated mothers are most likely to ensure the accurate perception and the ready acceptance of egalitarian gender-role values by their children. We conclude that egalitarian gender-role values enter Turkish migrant families through the education of the mothers. Specifically, education has both direct and indirect impact on the gender-role values of the next generation, through mutually reinforcing maternal values and role models. 


\section{Intercultural relations and value acculturation}

For a good understanding of cultural continuity and change, we should not only examine intergenerational transmission within migrant families but also the horizontal or oblique transmission of host cultural values. Taking a complementary perspective from intercultural relations, cross-cultural contact with German hosts entails the exposure of the second generation to more egalitarian gender-role values in the host society. In order to test the explanatory role of acculturation processes in intercultural relations, this study focuses on Berry's (2002) contact dimension of acculturation orientations. More specifically, we extend expectations from Bourhis' (et al, 1997) Interactive Acculturation Model (IAM) to predict value acculturation in the second generation. In previous research, Bourhis' IAM has mostly been used to predict relational outcomes at the group level, such as friendly or hostile inter-group attitudes. In this study, our dependent variable is the value orientation of the second generation. We reasoned that value change in the direction of the host culture should be more likely with higher degrees of cross-cultural contact, and with lower levels of perceived conflict in more harmonious intercultural relations. To test this expectation, behavioural as well as attitudinal measures of minority orientations towards cross-cultural contact were included in the analysis. In order to assess the degree of ethnic tension or conflict in intercultural relations, adolescents were asked to report their personal experience of ethnic discrimination. One key indicator of behavioural acculturation, and an important prerequisite for cross-cultural contact, is the acquisition of the host language. Hence, it was expected that adolescents who report better mastery of German, would have more egalitarian gender-role values (Hypothesis 3a). In addition, questions about ethnic distance were used as an attitudinal measure of adolescents' contact orientation, with ethnic distance indicating a separation type of acculturation orientations. It was expected that more ethnically separated adolescents would have more conservative gender-role values (Hypothesis 3b). Similarly, adolescents' experience of intercultural conflict, as indicated by higher levels of perceived discrimination, should also predict more conservative gender-role values (Hypothesis 3c).

Our findings fully confirm the third hypothesis about the impact of language acquisition on the acculturation of adolescents' values. As expected, Turkish-German adolescents who feel more proficient or confident in the German language, espouse more egalitarian gender-role values. This is in line with earlier findings associating language learning with an acculturative shift in the direction of host cultural values (e.g., Phinney \& Flores, 2002). Presumably, confidence in the host language increases the frequency and quality of cross-cultural interactions with hosts, which in turn enhance the accurate perception of host cultural values. Applying a two-process approach of transmission to value acculturation (Cashmore \& Goodnow, 1985), more frequent and friendly interactions with hosts should not only support the correct understanding, but also the acceptance of host cultural values by acculturating youth. In particular with regard to the acceptance of egalitarian gender-role values, we expected an additional negative effect of acculturation attitudes that stress ethnic distance or separation. As indicators of ethnic distance adolescents were asked whether they would accept a German marriage partner, or German names for their future children, and whe- 
ther they would like to return to Turkey in the future. None of these indicators, however, added to the explained variance in adolescents' gender-role values. Yet, we did find the expected effect of perceived discrimination, so that adolescents who report more personal experiences of discrimination in school, in shops or in their neighbourhoods, have more conservative gender-role values. This association of perceived hostility in intercultural relations with ethnic persistence successfully extends Bourhis' Interactive Acculturation Model to the prediction of value change in a migration context. It should be added immediately, however, that the support for Bourhis' IAM is limited to the Turkish-German boys. Coming back to the gendered pattern of value transmission in Turkish migrant families, we argued that not only intergenerational relations but also intercultural relations may be gendered. While the latter argument has not yet been extensively researched, some studies have reported gender differences in acculturation (e.g., Phinney \& Flores, 2002). In this study, one reason for the selective impact of inter-ethnic tension on the values of male adolescents could be the gendered meaning of ethnic identity, with conservative gender-role values being much more central to a male sense of ethnic loyalty. This would make sense since intergenerational solidarity in a traditional family model of material interdependence is more strongly enforced on males as future care-takers of their parents. A related reason refers to a double status threat. Turkish-German boys who feel more discriminated, may feel doubly threatened as members of a devalued ethnic minority group, and as men in a host society that disapproves of the superior status of males in a traditional, hierarchical family model. Since male adolescents may associate egalitarian gender-role values with perceived group threat in intercultural relations, the ethnic reaffirmation of conservative gender-role values by 'devalued males' would be in line with Bourhis' IAM.

As a general conclusion, we think that the combination of different explanations of adolescents' values from intergenerational as well as intercultural relations is a promising line of research, which should be developed further in future studies in other ethnic and host cultures. By bringing together both lines of explanation, our study was able to throw more light on gender differences in the transmission and acculturation of values. Thus, the values of adolescent girls were influenced most by direct intergenerational transmission from mother to daughter, while the values of adolescent boys are influenced more by their experience of ethnic discrimination and by normative reference to religious authority. For both girls and boys, however, language acculturation and value acculturation are closely connected, in that the acquisition of the host language enables the transmission of host cultural values. Studies that focus only on intergenerational relations within the family, or only on intercultural relations between migrant and host communities, may obscure our understanding of gender differences. More research is needed in order to test whether the observed gender differences in transmission and acculturation processes also hold for other value domains, and to what extent they generalize to other migrant groups with less traditional family values than the Turkish migrant group.

In addition, this study measures intergenerational value discrepancies, in the tradition of acculturation studies, along with intergenerational value correlations, in the tradition of transmission studies. The combination of both pieces of information in one and the same study enables a more balanced understanding of different pa- 
thways of value transmission in culturally diverse settings. Moreover, this double approach is crucial for a good understanding of gender differences. In particular, our theoretical expectations of effective value transmission along with adaptive change towards more egalitarian gender roles, are supported only for women. The male side of Turkish migrant families shows a reverse pattern of cultural continuity of conservative values in the absence of significant transmission within the family. Most importantly, our study allows a first critical test of the extent to with Kağıtçıbaşı's (1996) Model of Family Change applies to migrant families, where egalitarian gender role values are associated with a dominant western culture of independence. So far, the support for Kağıtçıbaşı's MFC in migrant families is mixed, in that the model explains much better the female perspective than the male perspective on gender-role values. Looking across gender, the key theoretical question to be answered in future studies is whether the egalitarian shift of second-generation women is part of a global trend towards a modern family model of interdependence, or whether these women will have to choose between westernizing in exchange for equal status, or reinventing a tradition that perpetuates gender inequality.

\section{References}

Aiken, L. S. \& West, S. G. (1991). Multiple regression: Testing and interpreting interactions. Newbury Park: Sage.

Andriessen, I. (2006). The impact of socio-cultural factors on school engagement. Utrecht University: Doctoral dissertation.

Ashmore, R. D. (1990). Sex, gender and the individual. In L. Pervin (Ed.) Handbook of personality: Theory and research. New York: Guilford Press, pp. 486-526.

Barber, B. K. (1996). Parental psychological control: Revisiting a neglected construct. Child Development, 67(6), pp. 3296-3319.

Baumrind, D. (1991). The influence of parenting style on adolescent competence and substance use. Journal of Early Adolescence, 11(1), pp. 56-95.

Baumrind, D. (1989). Rearing competent children. In W. Damon (Ed.), New directions for child development. San Fransisco: Jossey Bass.

Bengtson, V. L. (1975). Generation and family effects in value socialization. American Sociological Review, 40, pp. 358-371.

Bengtson, V. L. \& Dunham, C. C. (1986). Attitude similarity in three-generation families: Socialization, status inheritance or reciprocal influence? American Sociological Review, 51, pp. 685-698.

Berry, J. W., Poortinga, Y. H., Segall, M. H. \& Dasen, P. R. (2002). Cross-cultural psychology: Research and applications ( $2^{\text {nd }}$ Edition). Cambridge: Cambridge University Press, pp. 256-267.

Berry, J. W. (2002). Conceptual approaches to acculturation. In K.M. Chun, P.B. Organista \& G. Marin (Eds), Acculturation in theory, measurement and applied research. Washington DC: American Psychological Association.

Beutel, A. M. \& Marini, M. M. (1995). Gender and values. American Sociological Review, 60, pp. 436-448.

Birman, D. \& Trickett, E. J. (2001). Cultural transitions in first-generation immigrants: Acculturation of Soviet Jewish refugee adolescents and parents. Journal of Cross-Cultural Psychology, 32(4), 456-477. 
Branscombe, N., Schmitt, M. T., \& Harvey, R. D. (1999). Perceiving pervasive discrimination among African-Americans: Implications for group identification and well-being. Journal of Personality and Social Psychology, 77, pp. 135-149.

Brogan, D. \& Kutner, N. G. (1976) Measuring sex-role orientations: A normative approach. Journal of Marriage and the Family, 38, 31-40.

Boyd, R. \& Richardson, P. J. (1985). Culture and the evolutionary process. Chicago: University of Chicago Press.

Bourhis, R., Moise, C., Perreault S. \& Sénécal, S. (1997). Towards an interactive acculturation model: A social psychological approach. International Journal of Psychology, 32, pp. 369-386.

Bronfenbrenner, U. (1977). Toward an experimental ecology of human development. American Psychologist, July 1977, pp. 513-533.

Cashmore, J. A. and Goodnow, J. J. (1985). Agreement between generations: A two-process approach. Child Development, 56, 493-501.

Cavalli-Sforza, L. L. and Feldman, M. W. (1981). Cultural transmission and evolution: A quantitative approach. Princeton, NJ: Princeton University Press.

Chun, K. M. and Akutsu, P. D. (2003). Acculturation among ethnic minority families. In K.M. Chun, P.B. Organista, and G. Marin (Eds), Acculturation: Advances in theory, measurement and applied research. Washington, DC: American Psychological Association. pp. 95-119.

Delgato-Gaitan, C. (1994). Socializing young children in Mexican-American families: An intergenerational perspective. In P.M. Greenfield \& R.R. Cocking (Eds), Cross-cultural roots of minority child development. New York: Lawrence Erlbaum Associates, pp 41-54.

Farver, J. A., Bhadha, B. R. and Narang, S. K. (2002). East meets West: Ethnic identity, acculturation and conflict in Asian Indian families. Journal of Family Psychology, 16(3), pp. 338-350.

Felix-Ortiz, M. \& Newcomb, M.D. (1998). A multidimensional measure of cultural identity for Latino and Latina adolescents. Hispanic Journal of Behavioral Sciences, 16, pp. 99-107.

Fuligni, A., Tseng, V. \& Lam, M. (1999). Attitudes towards family obligations among American adolescents from Mexican, Chinese, Filipino and European backgrounds. Child Development, 70, pp. 1030-1044.

Gibbons, J. T., Stiles, D. A. \& Shkodriani, G. M. (1991). Adolescents' attitudes toward family and gender roles: An international comparison. Sex Roles, 25, pp. 625-643.

Greenfield, P. M. (1994). Independence and interdependence as developmental scripts: Implications for theory, research and practice. In P.M. Greenfield \& R.R. Cocking (Eds), Cross-cultural roots of minority child development. New York: Lawrence Erlbaum Associates, pp. 1-37.

Grusec, J. E. \& Goodnow, J. J. (1994). The impact of parental discipline methods on the child's internalization of values: A reconceptualization of current points of view. Developmental Psychology, 14, pp. 51-57.

Grusec, J. E., Goodnow, J. J. \& Kuczynski, L. (2000). New directions in the analysis of parenting contributions to children's acquisition of values. Child Development, 71, pp. 205-211.

Güngör, D. (in press). Parenting in migration. To appear in Applied Psychology.

Imamoğlu, E. O. \& Karakitapoğlu, A. Z. (1999). Value preferences from 1970s to 1990s: Cohort, generation and gender differences at a Turkish university. Turkish Journal of Psychology, 14, pp. 1-22.

Inglehart, R. \& Norris, P. (2003). Rising Tide: Gender equality and cultural change around the world. Cambridge: Cambridge University Press.

Jasinskaja-Lahti, I. (2000). Psychological acculturation and adaptation among Russian speaking immigrant adolescents in Finland. Helsinki: University of Helsinki, Department of Social Psychology 
Kağıtçıbaşı, C.. (1982). Old age security value of children: Cross-cultural socio-economic evidence. Journal of Cross-Cultural Psychology, 13, pp. 29-42.

Kağıtçıbaşı, Ç. (1996). Family and human development across cultures: A view from the other side. Hillsdale, N.J.: Lawrence Erlbaum Associates.

Kağıtçıbaşı, Ç. \& Ataca, B. (2005). Value of children and family change: A three-decade portrait from Turkey. Applied Psychology, 54(3), pp. 317-337.

Kloppenborg, R. \& Hanegraaff, W. J. (Eds) (1995). Female Stereotypes in Religious Traditions. Leiden: E. J. Brill.

Knafo, A. \& Schwartz, S. H. (2001). Value socialization in families of Israeli-born and Soviet-born adolescents in Israel. Journal of Cross-Cultural Psychology, 32, pp. 213-228.

Krampen, G. (1983). Eine Kurzform der Skala zur Messung normativer GeschlechtsrollenOrientierung. Zeitschrift für Soziologie, 12, pp. 152-156.

Kwak, K. (2003). Adolescents and their parents: A review of intergenerational family relations for immigrant and non-immigrant families. Human Development, 45, pp. 115-136.

Kwak, K. \& Berry, J. W. (2001). Generational differences in acculturation among Asian families in Canada. International Journal of Psychology, 36, pp. 152-162.

Lamont, M. (2000). The dignity of working men: Morality and the boundaries of race, class and immigration. New York: Russell Sage Foundation.

Leaper, C. \& Valin, D. (1996). Predictors of Mexican American mothers' and fathers' attitudes toward gender equality. Hispanic Journal of Behavioral Sciences, 18, pp, 343-355.

Levine, R. A. (1977). Child rearing as cultural adaptation. In H.P. Leiderman, S.R. Tulkin, and A. Rosenfeld (Eds), Culture and infancy: variations in the human experience. New York: Academic Press, pp. 15-27.

Levine, R. A., Miller, P. \& West, M. M. (1988). New directions for child development, Vol. 40, Parental behaviour in diverse societies. San Fransisco: Jossey Bass.

Maccoby, E. \& Martin, J. (1983). Socialization in the context of the family: Parent-child interaction. In E.M. Hetherington (Ed.) \& P.H. Mussen (Series Ed.), Handbook of child psychology, Volume 4, Socialization, personality and social development. New York: Wiley, pp. 1-101.

Meyers, S. (1996). An interactive model of religiosity inheritance: The importance of family context. American Sociological Review, 61(5), pp. 858-866.

Nauck, B. (1989) Intergenerational relationships in families from Turkey and Germany: An extension of the 'value of children' approach to educational attitudes and socialization practices. European Sociological Review, 5, 251-274.

Nauck, B. (2000). Eltern-Kind-Beziehungen in Migrantenfamilien - ein Vergleich zwischen griechischen, italienischen, türkischen und vietnamesischen Familien in Deutschland. In Sachverständigenkommission 6. Familienbericht (Eds), Empirische Beiträge zur Familienentwicklung und Akkulturation. Materialen zum 6. Familienbericht, Band 1. Opladen: Leske + Budrich, pp. 347-392.

Nauck, B. (2001). Intercultural contact and intergenerational transmission in immigrant families. Journal of Cross-Cultural Psychology, 32, pp. 320-331.

Nauck, B. \& Schönpflug, U. (1997). Familien in verschiedenen Kulturen. In B. Nauck \& U. Schönpflug (Eds), Familien in verschiedenen Kulturen. Stuttgart: Enke Verlag, pp.1-21.

Nguyen, N. \& Williams, H. L. (1989). Transition from East to West: Vietnamese adolescents and their parents. Journal of the American Academy of Child and Adolescent Psychiatry, 28(4), pp. 505-515.

Phalet, K. \& Hagendoorn, L. (1996). Personal adjustment to acculturative transitions: The Turkish experience. International Journal of Psychology, 31(2), pp.131-144.

Phalet, K. \& Hagendoorn, L. (2002). Constructing and mobilising ethno-religious identity and otherness. Utrecht: Ercomer Working Paper. 
Phalet, K. \& Kosic, A. (in press). Acculturation in European societies. In D. Sam \& J.W. Berry (Eds), The Cambridge handbook of acculturation psychology. Cambridge: Cambridge University Press.

Phalet, K. \& Schönpflug, U. (2001a). Intergenerational transmission in Turkish immigrant families: Parental collectivism, achievement values and gender differences. Journal of Comparative Family Studies, 32, pp. 489-504.

Phalet, K. \& Schönpflug, U. (2001b). Intergenerational transmission of collectivism and achievement values in two acculturating contexts: The case of Turkish families in Germany and Turkish and Moroccan families in the Netherlands. Journal of Cross-Cultural Psychology, 32, pp.186-210.

Phalet, K. and Swyngedouw, M. (2004). A cross-cultural analysis of immigrant and host values and acculturation orientations. In H. Vinken and P. Ester (Eds), Comparing cultures. Leiden: Brill, pp. 185-212,

Phinney, J. S. \& Flores, J. (2002). "Unpacking" acculturation: Aspects of acculturation as predictors of traditional sex-role attitudes. Journal of Cross-Cultural Psychology, 33, pp. 320-331.

Phinney, J. S., Ong, A., \& Maden, T. (2000). Cultural values and intergenerational value discrepancies in immigrant and non-immigrant families. Child Development, 71, pp. 528-539.

Phinney, J. S. \& Ong, A. (2002). Adolescent-parent disagreements and life satisfaction in families from Vietnamese- and European-American backgrounds. International Journal of Behavioral Development, 36, pp. 556-561.

Phinney, J. S. \& Vedder, P. (2006). Family relationships of adolescents and parents: Intergenerational discrepancies and adaptation. To appear in J.W. Berry, J.S. Phinney, D.L. Sam, $\&$ P. Vedder (Eds), Immigrant youth in cultural transition: Acculturation, identity and adaptation across national contexts. Lawrence Erlbaum Associates.

Piontkowski, U., Rohmann, A. \& Florack, A. (2002). Concordance of acculturation attitudes and perceived threat. Group Processes and Intergroup Relations, 5(3), pp. 221-232.

Portes, A. \& MacLeod, D. (1996). What shall I call myself? Hispanic identity formation in the second generation. Ethnic and Racial Studies, 19, pp. 523-547.

Rich, K. \& Forward, J. (1992). Acculturation and perceived intergenerational differences among Hmong youth. Journal of Cross-Cultural Psychology, 23(1), pp. 85-94.

Rohan, M. J. \& Zanna, M. P. (1996). Value transmission in families. In C. Seligman, J.M. O1son, and M.P. Zanna (Eds), The psychology of values: The Ontario Symposium, Volume 8 (pp. 253-276). Hillsdale, NJ: Erlbaum, pp. 253-276.

Rosenthal, D., Bell, R., Demetriou, A., \& Efklides, A. (1989). From collectivism to individualism? The acculturation of Greek immigrants in Australia. International Journal of Psychology, 24(1), pp. 57-71.

Rosenthal, D. Ranieri, N. \& Klimidis, S. (1996). Vietnamese adolescents in Australia: Relationships between perceptions of self and parental values, intergenerational conflict, and gender dissatisfaction. International Journal of Psychology, 31, pp. 81-91.

Rudy, D. \& Grusec, J. E. (2001). Correlates of authoritarian parenting in individualist and collectivist cultures and implications for understanding the transmission of values. Journal of Cross-Cultural Psychology, 32, pp. 202-212.

Sam, D. \& Virta, E. (2003). Intergenerational value discrepancies in immigrant and hostnational families, and their impact on psychological adaptation. Journal of Adolescence, 26, pp. 213-231.

Schönpflug, U. (2001). Intergenerational transmission: The role of transmission belts. Journal of Cross-Cultural Psychology, 32, pp. 174-185.

Sharma, A. (Ed.) (1987). Women in world religions. Albany: State University of New York Press. 
Schwartz, S. H. (1992). Universals in the content and structure of values: Theoretical advances and empirical tests in 20 countries. In M.P. Zanna (Ed.), Advances in experimental social psychology, Vol. 25 . San Diego, CA: Academic Press. pp. 1-64.

Sümer, N. \& Güngör, D. (1999). The impact of perceived parenting styles on attachment styles, self-evaluations and close relationships. Turkish Journal of Psychology, 14, pp. 35-58.

Thornton, A. \& Young-DeMarco, L. (2001). Four decades of trends in attitudes towards family issues in the US. Journal of Marriage and the Family, 63, pp. 1009-1037.

Trommsdorff, G. \& Nauck, B. (2005) (Eds). The value of children in cross-cultural perspective: Case studies from eight societies. Lengerich/Berlin: Pabst Science.

Van den Akker, P., Halman, L., \& De Moor, R. (1994). Primary relations in Western societies. In P. Ester, L. Halman \& R. De Moor (Eds), The individualizing society: Value change in Europe and North America. Tilburg: Tilburg University Press, pp. 97-127.

Van de Vijver, F. \& Phalet, K. (2004). Assessment in multicultural groups: The role of acculturation. Applied psychology, 53(2), pp. 215-236.

Verkuyten, M. (2001). Global self-esteem, ethnic self-esteem and family integrity: Turkish and Dutch early adolescents in the Netherlands. International Journal of Behavioral Development, 25 , pp. 357-366.

Whitebeck, L. B. \& Gecas, V. (1988). Value attributions and value transmission between parents and children. Journal of Marriage and the Family, 50, pp. 829-840.

Williams, J. E. \& Best, D. L. (1990). Measuring sex stereotypes: A multination study. Newbury Park: Sage Publications Inc.

Zagefka, H. \& Brown, R. (2002). The relationship between acculturation strategies and relative fit and intergroup relations: Immigrant-majority relations in Germany. European Journal of Social Psychology, 32, pp. 171-188.

Zick, A., Wagner, U., van Dick, R. \& Petzel, T. (2001). Acculturation and prejudice in Germany: Majority and minority perspectives. Journal of Social Issues, 57, pp. 541-557.

Submitted on/Eingereicht am: 23. 03.2006

Accepted on/Angenommen am: 21.07.2006

Address of the authors/Anschrift der Autorinnen:

Hanna Idema, M.A.

Prof. Dr. Karen Phalet, Full Professor

European Research Center on Migration and Ethnic Relations (ERCOMER)

University of Leuven and Utrecht University

Corresponding address/Korrespondenzadresse:

Prof. Dr. Karen Phalet

Faculty of Psychology and Education

University of Leuven

Tiensestraat 102

B-3000 Leuven

E-mail: K.Phalet@fss.uu.nl 